Research Paper

\title{
Effect of urban green space changes on the role of rainwater runoff reduction in Beijing, China
}

\author{
Biao Zhang*, Gao-di Xie, Na Li, Shuo Wang \\ Institute of Geographical Sciences and Natural Resources Research, Chinese Academy of Science, Beijing 100101, China
}

\section{H I G H L I G H T S}

- The green space area reduced by $199 \mathrm{~km}^{2}$ and became fragmented from 2000 to 2010 .

- The annual runoff reduction volume ranged from 132 million $\mathrm{m}^{3}$ to 198 million $\mathrm{m}^{3}$.

- The rainwater runoff reduction rate decreased by $6 \%$ with the land cover changes.

- The green space with larger LPI and AI is suitable for flooding risk reduction.

\section{A R T I C L E I N F O}

\section{Article history:}

Received 6 March 2014

Received in revised form 3 March 2015

Accepted 31 March 2015

Available online 21 April 2015

\section{Keywords:}

Urbanization

Urban green spaces

Landscape pattern

Rainwater runoff

Beijing

\begin{abstract}
A B S T R A C T
The effects of urban green spaces on stormwater runoff have increasingly attracted attention because of climate change and rapid urbanization conditions. This study investigates the spatial-temporal changes of urban green spaces in Beijing and estimates their effects on rainwater runoff reduction based on an empirical model. Results indicate that green spaces in Beijing decreased by $199 \mathrm{~km}^{2}$ from 2000 to 2010 and that landscape patches became increasingly isolated and fragmented. The volume of rainwater runoff controlled by urban green spaces first increased and then decreased with the increase in summer rainfall. The runoff reduction rate continuously decreased from 23\% in 2000 to $17 \%$ in 2010, which is mainly attributed to the composition changes in urban green spaces. In addition, an immense regional difference that is closely related to the changes in the largest patch and aggregation indices of urban green spaces are observed in different regions. This study recommends an optimal landscape pattern of urban green spaces for the planning and management of green spaces in highly urbanized areas.
\end{abstract}

(c) 2015 Elsevier B.V. All rights reserved.

\section{Introduction}

Rapid urbanization worldwide has become a critical issue in the 21st century (Grimm et al., 2008; Parrish \& Zhu, 2009). The world urban population is expected to increase by $84 \%$ from 3.4 billion in 2009 to 6.3 billion in 2050 (United Nations, 2010). The number of megacities has significantly increased since 1970, with the newest ones emerging in developing countries (United Nations, 2012). Urban development involves the replacement of vegetated soils with impermeable surfaces; this process can exert profound influences on the biogeochemical cycle, hydrological process, climate change, and biodiversity in terrestrial ecosystems at multiple scales (Alberti, 2009; Kuang, Liu, Zhang, Lu, \& Xiang, 2013; Pickett et al., 2011). The increase in summer flood risk in an urban environment is

\footnotetext{
* Corresponding author. Tel.: +86 10 64888157; fax: +86 1064888202.

E-mail addresses: zhangbiao@igsnrr.ac.cn (B. Zhang), xiegd@Igsnrr.Ac.Cn (G.-d. Xie), lin.12b@Igsnrr.Ac.Cn (N. Li), lin.Delay1107@163.Com (S. Wang).
}

a major concern in many regions of the world (Pitt, 2008; Wheater \& Evans, 2009). The United Nations (2012) reported that flooding has become the most frequent and significant hazard for 633 of the largest cities or urban agglomerations worldwide. Several highly urbanized areas in China, such as Beijing (Gu, Li, Zhou, \& Wu, 2013; Li, 2012), Shanghai (Quan et al., 2010; Yin, Yin, Xu, \& Wen, 2011), and Guangzhou (Guo \& Deng, 2011; Zhang \& Ouyang, 2011), have become increasingly prone to flooding in recent years as a result of short-term heavy rains. Thus, immense efforts are focused on improving conventional and innovative stormwater management practices to decrease the runoff volume associated with developed pervious and impervious land covers (Battiata, Collins, Hirschman, \& Hoffmann, 2010).

The effects of vegetation on surface water runoff have been extensively studied (Armson, Stringer, \& Ennos, 2013; City of Seattle, 2008; Inkiläinen, McHale, Blank, James, \& Nikinmaa, 2013). The use of urban green space has been increasingly identified as a measure to reduce runoff and mitigate the negative effects of urbanization on the hydrology of urban areas (Bartens, Day, Harris, 
Dove, \& Wynn, 2008; Mentens, Raes, \& Hermy, 2006; Zhang, Xie, Zhang, \& Zhang, 2012). Ellis, Leguédois, Hairsine, and Tongway (2006) demonstrated that tree belts can reduce runoff from an agricultural grassed slope by $32 \%$ to $68 \%$ in a 1 -in-10-year storm event ( $24.5 \mathrm{~mm}$ in $30 \mathrm{~min}$ ) and by $100 \%$ in a one-in-two-year storm event $(48 \mathrm{~mm} / \mathrm{h}$ for $13 \mathrm{~mm})$. Clearing and planting five vegetated Northern Philadelphia vacant lots to retain stormwater decreased runoff by an average of $30 \%$, with an average peak runoff reduction at nearly 24\% from June 2005 to May 2006 (Yang \& Myers, 2007). The trees and their associated tree pits in $9 \mathrm{~m}^{2}$ Manchester plots reduced runoff from asphalt by as much as $62 \%$, whereas grass almost totally eliminated surface runoff (Armson et al., 2013).

Directly measuring how efficiently landscapes reduce runoff is costly in terms of field and laboratory time. Thus, computing models such as the stormwater management model (SWMM), SWAT, soil conservation service curve number (SCS-CN), and CITYgreen have been widely used. Gill, Handley, Ennos, and Pauleit (2007) modeled the potential runoff reduction produced by trees in Manchester, United Kingdom; they determined that a $10 \%$ increase in tree cover in high density residential areas can lower surface runoff by $5.7 \%$ in a $28 \mathrm{~mm}$ event. $\mathrm{Li}$, Li, Chen, Yuan, and Xu (2009) used the CITY-green model and determined that the annual surface runoff decreased by 30\% from 1990 to 2005; the peak flow decreased by over $40 \%$ in Shenzhen, China. The aforementioned studies highlighted the value of urban green spaces in reducing rainwater runoff but failed to consider the effects of landscape patterns (i.e., size, shape, or spatial arrangement of vegetation patches) on the role of runoff reduction.

Landscape ecology and catchment hydrology are disciplines that deal with patterns, processes, interactions, and functional implications on different scales (Schröder, 2006). Many studies have shown that landscape structures are significant factors that affect surface runoff and spatial variety (Fiener, Auerswald, \& Van Oost, 2011; Fohrer, Haverkamp, \& Frede, 2005; Jencso et al., 2009; Lexartza-Artza \& Wainwright, 2009; Nippgen, McGlynn, Marshall, \& Emannuel, 2011; Ziegler et al., 2007). Investigating the relationships between vegetation structural attributes, soil surface properties, and hillslope hydrologic functions in a semiarid Mediterranean landscape, Bautista, Mayor, Bourakhouadar, and Bellot (2007) found an inverse relationship between patch density and runoff and that both runoff and sediment yields increase as the spatial pattern of vegetation coarsens. With simulated rainfall experiments, Guo, Xu, and Lv (2007) concluded that the spatial structure of an urban underlying surface largely influences the rainfall infiltration rate. Liu, Wang, and Duan (2011) demonstrated that a clear relationship exists between landscape patterns and flood storage capacities in the Dongting Lake area in China. Thus, planning and designing the optimal landscape pattern of urban green spaces to facilitate positive runoff regulation are now urgent necessities for city managers.

The present study mainly focuses on the landscape pattern changes of urban green spaces (including landscape types and metrics) in Beijing as well as their effects on rainwater runoff reduction. We attempt to develop an empirical model for urban landscape pattern and rainwater runoff and to examine the effect of urban land cover changes on the role of rainwater runoff reduction at the local level. Using the inner city of Beijing from 2000 to 2010 as a case study, this study aims to achieve the following objectives: (1) to explore the temporal and spatial changes of urban green spaces in established areas in Beijing, (2) to estimate the amount and capacity of urban green spaces for rainwater runoff reduction, and (3) to analyze the regional differences in rainwater runoff reduction across different regions.

The rest of this paper is organized as follows. Section 2 provides a background of the study area and the assessment methods. Section
3 presents the results. Sections 4 and 5 provide the discussion and conclusions, respectively.

\section{Materials and methods}

\subsection{Study area}

Beijing is located in Northern China at $39^{\circ} 38^{\prime}$ to $41^{\circ} 05^{\prime} \mathrm{N}$ and occupies a total area of $16,807 \mathrm{~km}^{2}$. The population was almost 16.95 million in 2010, the average population density was 1033 people $/ \mathrm{km}^{2}$, and the urbanization rate was $85.9 \%$ (Beijing Municipal Statistical Bureau, 2010). The road network in Beijing consists of ring roads and radials as arteries. The road around the Forbidden City is the first ring, and the ring roads beyond this area are the second, third, fourth, fifth, and sixth ones, which were termed as such relative to the radial distance of each road from the city center. Beijing underwent rapid urbanization with the implementation of the Reforms and Opening-up Policy. The urban area of Beijing increased from $183.84 \mathrm{~km}^{2}$ in 1973 to $1209.97 \mathrm{~km}^{2}$ in 2005; the built-up area has increased by $1026.13 \mathrm{~km}^{2}$ over the past 32 years, with an annual expansion rate of $32.07 \mathrm{~km}^{2}$ (Mu et al., 2007). Official statistics show that the built-up area of Beijing expanded from $109 \mathrm{~km}^{2}$ in 1949 to $1350 \mathrm{~km}^{2}$ in 2009 (National Bureau of Statistics of China, 2009). Considering that the high-density urban locale is the dominant landscape within the sixth ring road (Xiao, Ouyang, Cai, \& Li, 2007), we adopted this region as the study area and divided it into five zones in accordance with the five ring roads (Fig. 1).The city has an average annual precipitation of $554.5 \mathrm{~mm}$, nearly $80 \%$ of which is concentrated between June and September (Sun, Feng, Yang, \& Wu, 2007). Beijing has suffered from a gradual decrease in annual precipitation from 1950 to present because of global climate change (Yue, 2007). In addition, extreme rainstorms frequently occur in urban centers (Zhong, Jia, \& Li, 2013), thereby increasing flood risk sharply (Hu, Xuan, \& Zhu, 2013). For example, the largest rainstorm in Beijing in the last 61 years occurred on July 21, 2012, and generated an average daily rainfall of $215 \mathrm{~mm}$ in the urban area, with the largest cumulative rainfall of $460 \mathrm{~mm}$ in Hebei village of Fangshan county. This rainstorm was referred to as the "7.21" catastrophic natural disaster because of its severe consequences (Li, 2012). Furthermore, 17 heavy rainstorms were experienced by Beijing during the recent 10 -year period (Chen et al., 2011; Lan \& Yang, 2009), including the "7.10" event in 2004 (the maximum $1 \mathrm{~h}$ precipitation exceeded $90 \mathrm{~mm}$ ), " 7.31 " in 2006 (the maximum $1 \mathrm{~h}$ precipitation was $105 \mathrm{~mm}$ ), and "6.23" in 2011 (the maximum $1 \mathrm{~h}$ precipitation reached $128 \mathrm{~mm}$ ). Nineteen urban road water-logging events (road drainage systems cannot timely drain heavy or continuous rainfall resulted in urban traffic congestion or interruption) occurred in Beijing during the flood seasons (i.e., June, July, and August) from 2007 to 2010 (You, Shi, \& Wu, 2001). These rainstorms resulted in dozens of deaths and immense losses in social welfare.

Vegetated areas present benefits, including water infiltration and storage in the soil, runoff reduction, nutrient and pollutant removal, and groundwater quality. The urban green space area in Beijing has decreased to $14.68 \%$ in the past 20 years because of rapid urbanization (Fu, 2012). However, the number and area of city parks increased substantially from 2000 to 2010, with the expansion of urban built-up area boundary. The urban center park area has increased by 5188.44 ha for the past 10 years with an expansion rate of 6.36\% per year (Mao, Song, Yang, \& Zhao, 2012). However, the green landscape distribution still remains uneven, the community structure is simple, and the landscape diversity index is low (Wang et al., 2010). In the past decade, city managers have focused greatly on the construction of drainage pipe networks given the lack of clear recognition of the positive roles of urban green spaces 


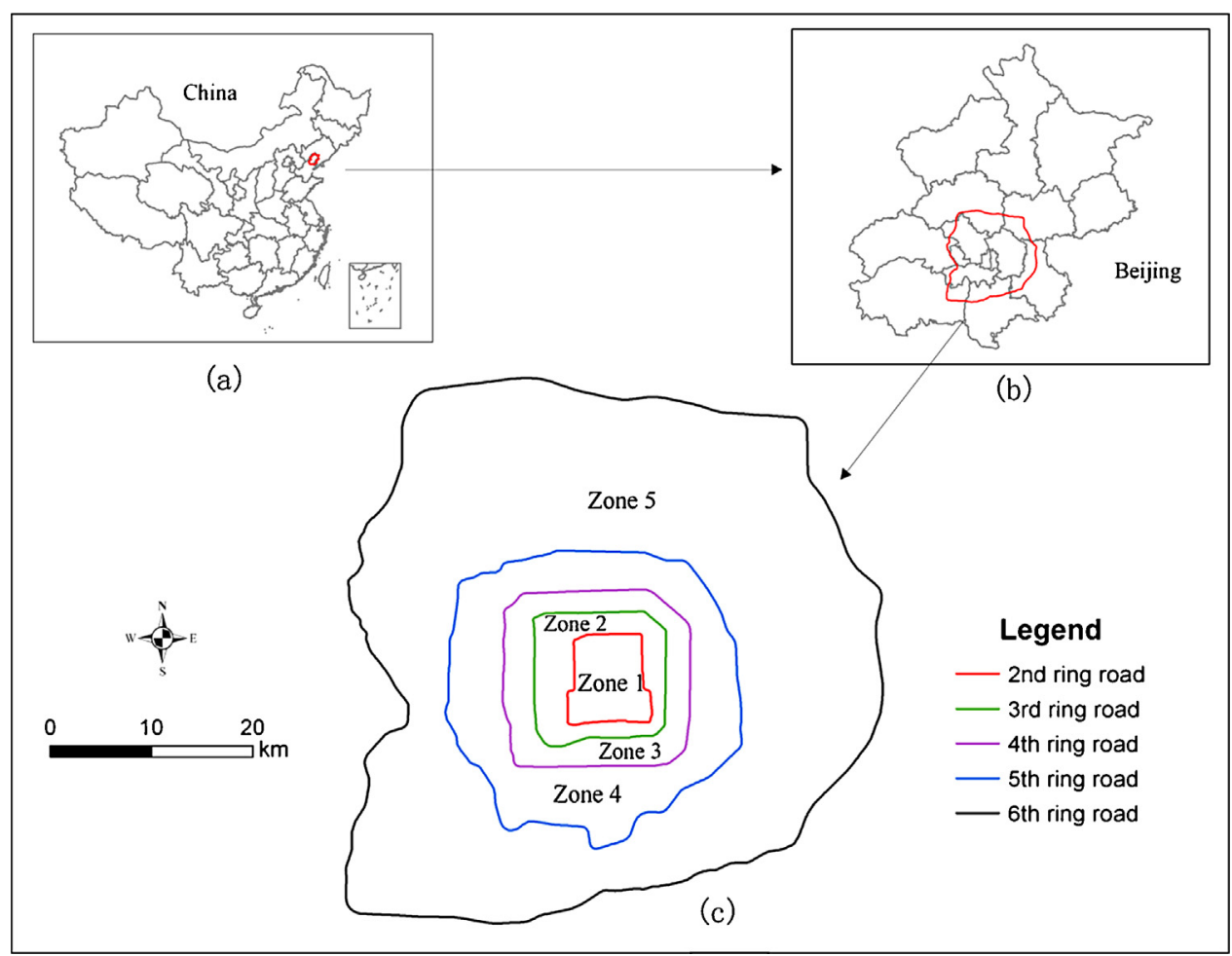

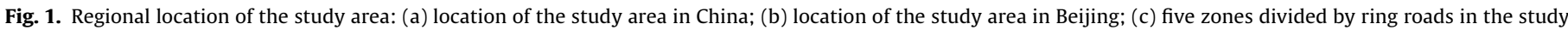

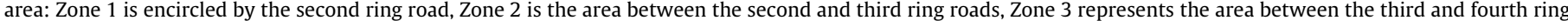
roads, Zone 4 is the area between the fourth and fifth ring roads, and Zone 5 represents the area between the fifth and sixth ring roads.

in hydrological regulations (Li, 2012; Zhang et al., 2012). This condition has resulted in increased financial burden, decreased low flow, and diminished groundwater recharge. Therefore, a comprehensive understanding and assessment of land cover change effects on rainwater runoff is crucial to the planning, management, and sustainable development of urban green spaces.

\subsection{Land cover area}

Digital land cover maps (Fig. 2) were generated from a multitemporal and multi-spectral dataset to serve as the bases for the hydrological impact evaluation of land cover changes. RapidEye images (with $2.5 \mathrm{~m}$ resolution) from 2000, 2005, 2008, and 2010 were used. Image pre-processing was completed with ERDAS Imagine 9.3 software. Satellite images were generated by applying coefficients for radiometric calibration, geometric rectification, and mosaic. First, we rectified these multispectral and panchromatic images with 20 ground control points through the nearest neighbor resampling algorithm and ascertained a less than 0.5 pixel root mean square error through image-to-image registration. After the rectification, a mosaic was created using the rectified images, which we re-sampled to a $5 \mathrm{~m}$ resolution and projected through the Universal Transverse Mercator zone 110E, WGS ellipsoid. Finally, the boundary of the sixth ring road was used to clip these images for the study area.

The supervised classification method with maximum likelihood clustering and digital elevation model (DEM) data was employed as a hybrid method to classify images and generate land cover maps. Post-classification analysis was performed to create the trend map of the land cover. Land cover categories were determined as farm, forest, grass, wasteland, impervious surface, and water. Pure pixels were selected as the training sample instead of mixed pixels. Mixed classes, such as forest and grass, were separated using the DEM data. The spatial mapping of urban green areas in 2010 from the
Beijing Municipal Bureau of Landscape and Forestry was performed to assist the image classification and validate the final results. Each image was classified through the same method.

The overall accuracy and kappa value $\left(K_{\mathrm{ap}}\right)$ were selected as the evaluation criteria for image classification. An error matrix was generated based on the test samples for each land cover map. The overall accuracy that ranged from 0 to 1 was computed by dividing the total number of correct pixels by the total number of pixels in the error matrix. Kappa analysis is a discrete multivariate technique used in accuracy assessment, and $K_{\mathrm{ap}}$ is between -1 and 1 . If test samples are in perfect agreement, the values of overall accuracy and $K_{\mathrm{ap}}$ are equal to 1 . The overall classification accuracy of each image in this study was over $92 \%$ with $K_{\text {ap }}$ of more than 0.82 . The accuracy requirements were thus satisfied.

\subsection{Volume of rainwater runoff reduction}

Selecting effective methodologies for investigating the effects of land use changes on storm runoff generation remains an urgent problem. Recent proposals have largely focused on adopting computing models to address issues such as stormwater runoff generation and volume (Soulis, Valiantzas, Dercas, \& Londra, 2009; Yang \& Myers, 2007). However, the accuracy of runoff modeling is constrained by data availability, and the quantitative means to predict the storm runoff generated in a highly fragmented urban landscape are limited. The present study combines an empirical model with landscape metrics to estimate the volume of rainwater runoff generation from different land cover types.

Rainwater runoff is precipitation that does not sink into the ground upon landfall. Land cover, including forests, agricultural activities, and urban development, is the primary control in generating runoff (Fox et al., 2012). A soft ground of vegetated areas allows water to seep through as the vegetation absorbs water and releases it into the air through evapotranspiration (Bolund 


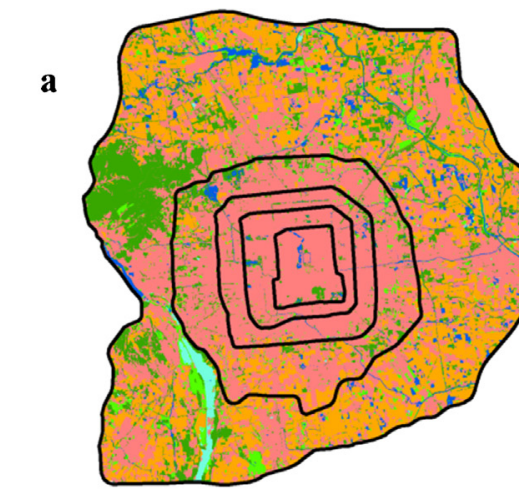

b

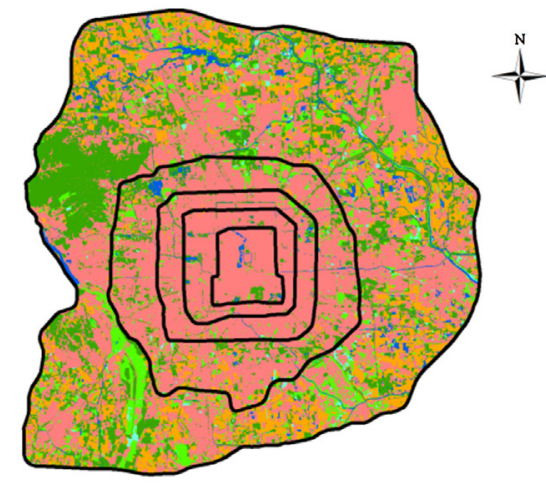

c
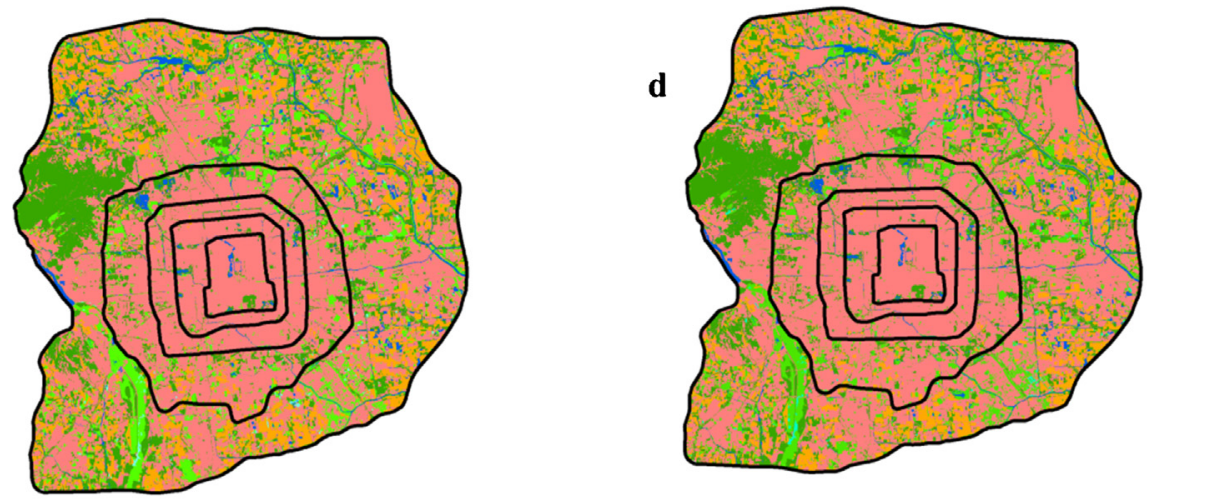

$\square$ Ring Roads

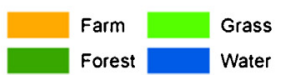

Wasteland

Impervious surface

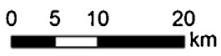

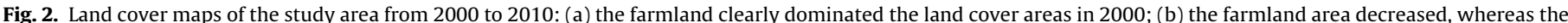
forest and grassland areas increased in 2005; minor changes in land cover were observed between 2008 (c) and 2010 (d).

\& Hunhammar, 1999). Therefore, the increased creation of green areas has been proposed as a response to recent calls for ecological and green urbanization (Zhang et al., 2012). And in general, the rainwater runoff coefficient of green spaces in Beijing is viewed as $10 \%$, whereas that of hard surfaces as $80 \%$ (Yin, 2009). In addition, a multitude of case studies have been conducted in Beijing to investigate rainwater runoff with different land uses (Gao \& Wang, 1993; Sun, Wu, Xiao, \& Teng, 2009; Yu \& Wang, 1999; Zhang et al., 2002). For example, Yang, Shi, Li, and Zhang (1994) measured actual rainwater runoff in six watersheds with the vegetation of a natural secondary shrubbery forest in Xishan mountain (located in the western suburbs of Beijing, and approximately $20 \mathrm{~km}$ distant

Table 1

Rainwater runoff coefficients for different land cover types in Beijing.

\begin{tabular}{|c|c|c|c|}
\hline Land cover & Underlying surface & Rainwater runoff coefficient & Case study \\
\hline Forest & $\begin{array}{l}\text { Conifer (Larch) } \\
\text { Conifer (Platycladus) } \\
\text { Broadleaf (Black Locust) } \\
\text { Broadleaf (Birch) } \\
\text { Mixed forest } \\
\text { Shrub } \\
\text { Mean }\end{array}$ & $\begin{array}{l}0.05 \\
0.25 \\
0.03-0.05 \\
0.21 \\
0.03 \\
0.06-0.08 \\
0.1\end{array}$ & $\begin{array}{l}\text { Gao and Wang (1993) } \\
\text { Yu and Wang (1999) } \\
\text { Gao and Wang (1993) } \\
\text { Yu and Wang (1999) } \\
\text { Yu and Wang (1999) } \\
\text { Yang et al. (1994) }\end{array}$ \\
\hline Grass & $\begin{array}{l}\text { Natural grassland } \\
\text { Artificial grassland } \\
\text { Residential quarter } \\
\text { Mean }\end{array}$ & $\begin{array}{l}0.04-0.19 \\
0.03-0.07 \\
0.23-0.34 \\
0.17\end{array}$ & $\begin{array}{l}\text { Sun et al. (2009) } \\
\text { Sun et al. (2009) } \\
\text { Zhang et al. (2002) }\end{array}$ \\
\hline Farm & $\begin{array}{l}\text { Corn } \\
\text { Corn } \\
\text { Mean }\end{array}$ & $\begin{array}{l}0.56 \\
0.49 \\
0.53\end{array}$ & $\begin{array}{l}\text { Sun et al. (2009) } \\
\text { Huang et al. (2003) }\end{array}$ \\
\hline Wasteland & $\begin{array}{l}\text { Non-forest land } \\
\text { Bare area } \\
\text { Bare field } \\
\text { Mean }\end{array}$ & $\begin{array}{l}0.66 \\
0.71 \\
0.63 \\
0.67\end{array}$ & $\begin{array}{l}\text { Yu and Wang (1999) } \\
\text { Huang et al. (2003) } \\
\text { Sun et al. (2009) }\end{array}$ \\
\hline $\begin{array}{l}\text { Impervious } \\
\text { surface }\end{array}$ & $\begin{array}{l}\text { Roof } \\
\text { Road } \\
\text { Mean }\end{array}$ & $\begin{array}{l}0.80-0.98 \\
0.87-0.97 \\
0.9\end{array}$ & $\begin{array}{l}\text { Dong et al. (2008) } \\
\text { Dong et al. (2008) }\end{array}$ \\
\hline
\end{tabular}

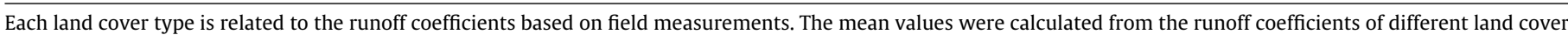
types using an arithmetic method. 
from the Forbidden City). Huang, Zhou, Zhang, and Zhang (2003) investigated the storm runoff from the agricultural field plots of the Guanting Watershed in Beijing under simulated rainfall conditions. The measured runoff coefficients in field studies have been collected at different sites and periods (Table 1), we derive the average value of the runoff coefficient for each land cover type, in order to simplify the calculation for runoff generation.

We have to consider land cover patterns in the runoff estimation when moving from single fields to large spatial scales. The effects of patchiness, spatial organization of patches, and linear structures on the surface runoff response are most visible on small headwater catchments (Fiener et al., 2011). A study in the Dongting Lake area (located in the south beach of the middle reaches of the Yangtze River, across Hunan and Hubei provinces) in China confirmed the relationship between landscape patterns and flood storage capacities (Liu et al., 2011). The results revealed that the correlations between the amount of flood retention and largest patch index (LPI) and aggregation index (AI) were the largest, with correlation values of 0.77 and 0.75 , respectively. Therefore, we introduced LPI and AI as the revised coefficients in the empirical model.

$P A I_{i}=L P_{i} \times A I_{i}$

$P A R I_{i}=\frac{P A I_{i}-P A I_{\text {min }}}{P A I_{\max }-P A I_{\min }}$

where $P A I_{i}$ is the aggregative index of the LPI and $\mathrm{AI}$ in the $i$ th urban green space patch, $P A R I_{i}$ is the revised coefficient of land cover patterns calculated from the normalization processing, and $L P I_{i}$ and $A I_{i}$ are the largest patch and aggregation indexes in the $i$ th urban green space patch, respectively.

Nearly $80 \%$ of the annual precipitation in Beijing is concentrated between June and September. Summer rainfall $(P)$ can be obtained from the sum of the monthly precipitation values between June and September. Therefore, the volume of rainwater runoff reduction $(R)$ can be calculated using the runoff difference between the impervious surface $\left(\gamma_{h}\right)$ and green spaces $\left(\gamma_{i}\right)$ in Formula (3). The total amount of rainwater runoff reduction (TR) and the ratio of runoff reduction (RR) can be determined using Formulas (4) and (5), respectively.

$$
\begin{aligned}
& R_{i}=P \times P A R I_{i} \times\left(\gamma_{h}-\gamma_{i}\right) \times A_{i} \times 10^{3} \\
& T R=\sum_{i=1}^{n} R_{i} \\
& R R=\frac{T R \times 100}{\sum_{i=1}^{n}\left(10^{3} \times P \times A_{i}\right)}
\end{aligned}
$$

where $T R$ is the total volume of rainwater runoff reduction $\left(\mathrm{m}^{3}\right), R_{i}$ is the runoff volume controlled by the $i$ th landscape patch $\left(\mathrm{m}^{3}\right), R R$ represents the ratio of runoff reduction (\%), $\gamma_{i}$ is the runoff coefficient of the $i$ th landscape patch (Table 1$), P$ is the summer rainfall $(\mathrm{mm}), A_{i}$ is the area of the $i$ th landscape patch $\left(\mathrm{m}^{2}\right)$, and $n$ is the number of land cover patches.

\section{Results}

\subsection{Land cover changes}

The spatial distribution of an urban land cover in Beijing (Fig. 2) shows that for all periods, the constructed part occupied the largest surface area at nearly $50-60 \%$ of the study area. As shown in Fig. 2, most of the land cover was concentrated in the core part of the city. Impervious lands occupied most of the area, followed by farmlands and forestlands. The largest net loss from 2000 to 2005 was observed in the farmlands $\left(-295 \mathrm{~km}^{2}\right)$, whereas the largest net gains were observed in the forestlands and grasslands. Most of these gains were from the farmlands (Table 2). The largest loss between 2005 and 2010 persisted in the farmlands. The surface area loss was approximately a quarter of the area from 2000 to 2005. The forest area also decreased substantially. Unlike the data from 2000 to 2005, the largest gain between 2005 and 2010 was observed in impervious surfaces with a net increase of $142 \mathrm{~km}^{2}$. Much of the urban growth in the earlier period was at the expense of the farmlands. However, urban land covers from farmlands and wastelands increased in the latter period. Overall, a large area of farmland and water was replaced by impervious surfaces from 2000 to 2010 . These land cover changes mainly occurred in Zone 5 located between the fifth and sixth ring roads. Grass areas and forests benefited most from the farmland and wasteland losses (Fig. 2). Furthermore, a certain degree of swapping between forest, grass, and farmland was observed outside the fifth ring road, with virtually no growth in the other parts (Table 2).

The total area of the urban green spaces in Beijing continuously decreased in the $2000-2010$ period (Fig. 3), resulted in a continual decrease from $1041 \mathrm{~m}^{3}$ in 2000 to $842 \mathrm{~km}^{2}$ in 2010 . Almost $20 \mathrm{~km}^{2}$ of the urban green spaces were replaced by impervious surfaces annually. The landscape metrics on the patch level were calculated using FRAGSTATS (Version 3.3). The class-specific AI is independent of landscape composition and provides a quantitative basis for correlating the spatial pattern of each class with a specific process (He, DeZonia, \& Mladenoff, 2000). In this study, the AI of the urban green spaces constantly decreased through time from 92 in 2000 to 88 in 2010. The LPI, which quantifies landscape composition through the percentage of total landscape area encompassed by the largest patch, is widely used as an indicator of landscape fragmentation as well. The LPI of the urban green spaces in this study decreased substantially from 7.5 to 5.2 in the 2000-2005 period, whereas a gradually descending trend was observed from 2005 to 2010. Therefore, the landscape patches of the urban green spaces in Beijing were increasingly isolated and fragmented over the 11 year span.

\subsection{Rainwater runoff reduction across different years}

Many studies have confirmed that urban green spaces can play a positive role in reducing rainwater runoff. The spatial-temporal patterns in urban green spaces significantly influence surface runoff generation as well. We obtained summer rainfall data from 2000 to 2010 (Fig. 4) using the monthly rainfall data published on the China Meteorological Data Sharing Service System (http://cdc.cma. gov.cn).

The urban green spaces could reduce rainwater runoff by 132-198 million $\mathrm{m}^{3}$. The urban green spaces provided the largest stormwater runoff reduction in 2008 and controlled the lowest runoff in 2000. The urban green spaces reduced storm runoff

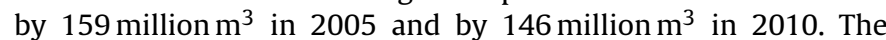
increased built-up areas resulted in decreased urban green spaces, whereas the summer precipitation clearly showed an increasing trend. The estimated runoff reduction volume increased by 66 million $\mathrm{m}^{3}$ and decreased by 52 million $\mathrm{m}^{3}$ based on the land cover distribution pattern between 2000 and 2010. We also adopted the runoff reduction rate (i.e., the percentage of the runoff reduction amount of the annual summer rainfall) to analyze the capacity of urban green spaces for runoff regulation. The green spaces in 2000 indicated the highest runoff reduction rate at $23.43 \%$. The next factors were the urban green spaces in 2005 and 2008, which were measured at $22.59 \%$ and $19.15 \%$, respectively. The minimum runoff reduction rate was $16.89 \%$ in 2010 . 
Table 2

Changes in urban land cover areas in Beijing from 2000 to $2010\left(\mathrm{~km}^{2}\right)$.

\begin{tabular}{|c|c|c|c|c|c|c|c|}
\hline \multirow[t]{2}{*}{ Year } & \multicolumn{7}{|c|}{ Land cover } \\
\hline & Forest & Grass & Farm & Wasteland & Water & Impervious surface & Green space \\
\hline 2000-2005 & 135.20 & 91.96 & -295.09 & 2.13 & -11.56 & 77.37 & -65.80 \\
\hline 2005-2010 & -73.40 & 31.29 & -76.34 & -14.23 & -3.88 & 141.83 & -77.28 \\
\hline 2000-2010 & 61.81 & 123.25 & -371.44 & -12.10 & -20.71 & 219.19 & -198.49 \\
\hline
\end{tabular}

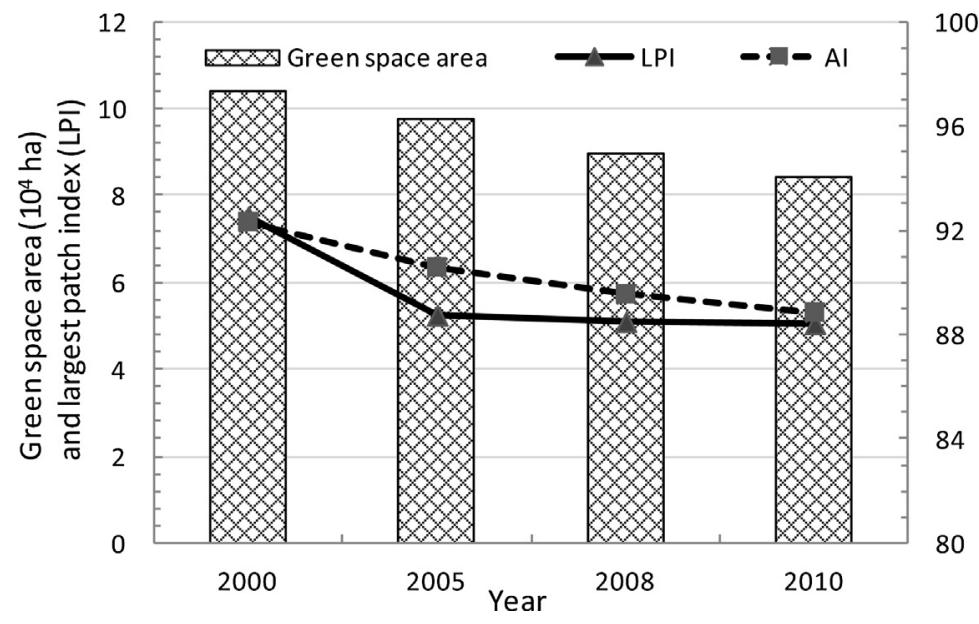

100

96

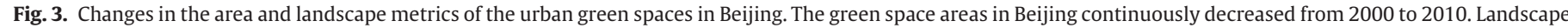
metrics (i.e., LPI and $\mathrm{AI}$ ) also showed descending trends.

The changes in urban green spaces and their capacity for runoff reduction (Figs. 3 and 4, respectively) indicate the changing trends of the urban green space area in Beijing and the role of rainwater runoff reduction. The magnitude of rainwater runoff reduction first increased and then decreased. This condition is mainly correlated with the changes in summer rainfall. However, the reduction ratio of rainwater runoff decreased from $23 \%$ to $17 \%$. This variation is primarily attributed to the changes in the types and areas of urban green spaces. In 2000, a majority of the urban green spaces were occupied by farmlands, which accounted for larger runoff coefficients compared with forests and grasslands. Low levels of farmland areas were maintained, and the area percentages of forests and grasses increased in the following period. Thus, the changes in the runoff reduction capacity resulted primarily from agricultural lands, which were partly compensated by the increase in grass areas.

\subsection{Rainwater runoff reduction across different regions}

The capacities for rainwater runoff reduction across different districts (Fig. 5) show that, the urban green space in Zone 5 (between the fifth and sixth ring roads) recorded the maximum runoff reduction ratio (average of $28 \%$ ). The next area was Zone 1 (inner part of the second ring road), followed by Zone 4 (between

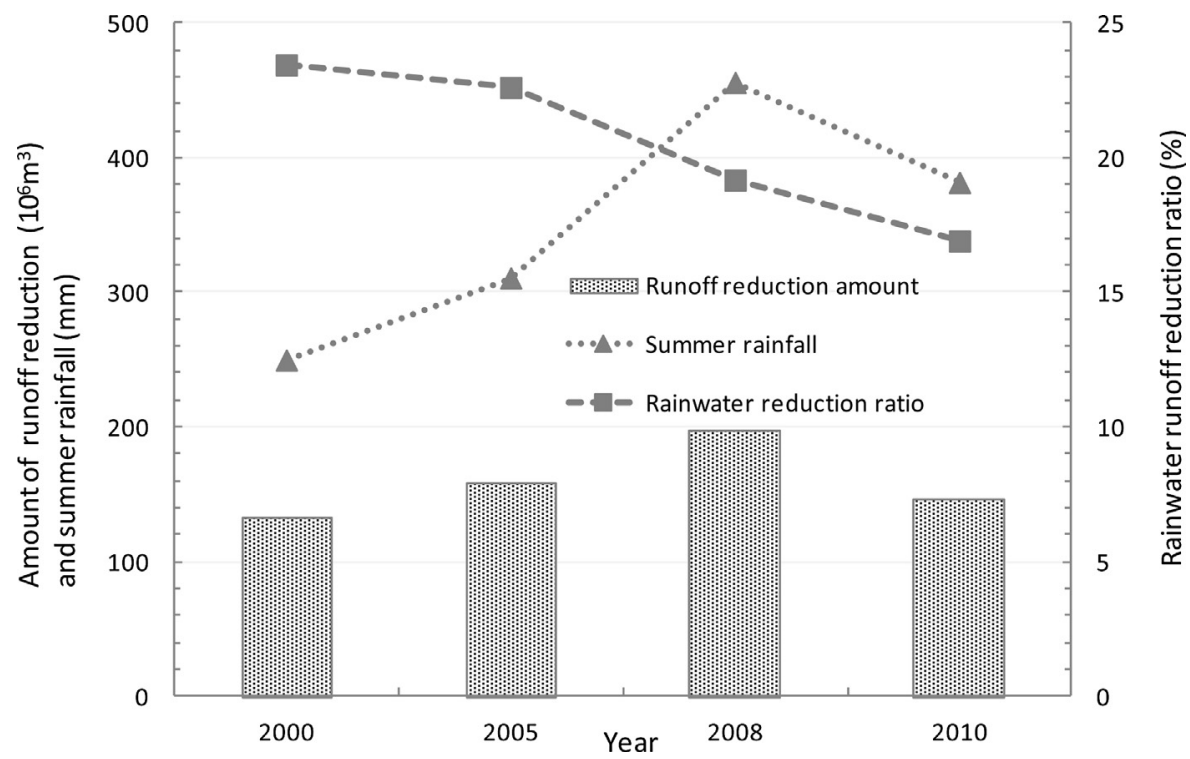

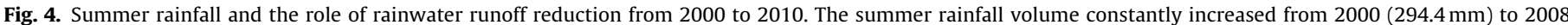

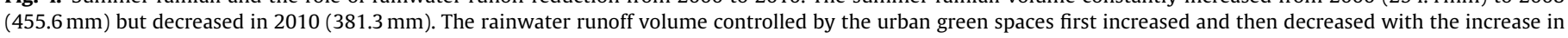
summer rainfall. Meanwhile, the runoff reduction rate continuously decreased from 23\% in 2000 to $17 \%$ in 2010 . 


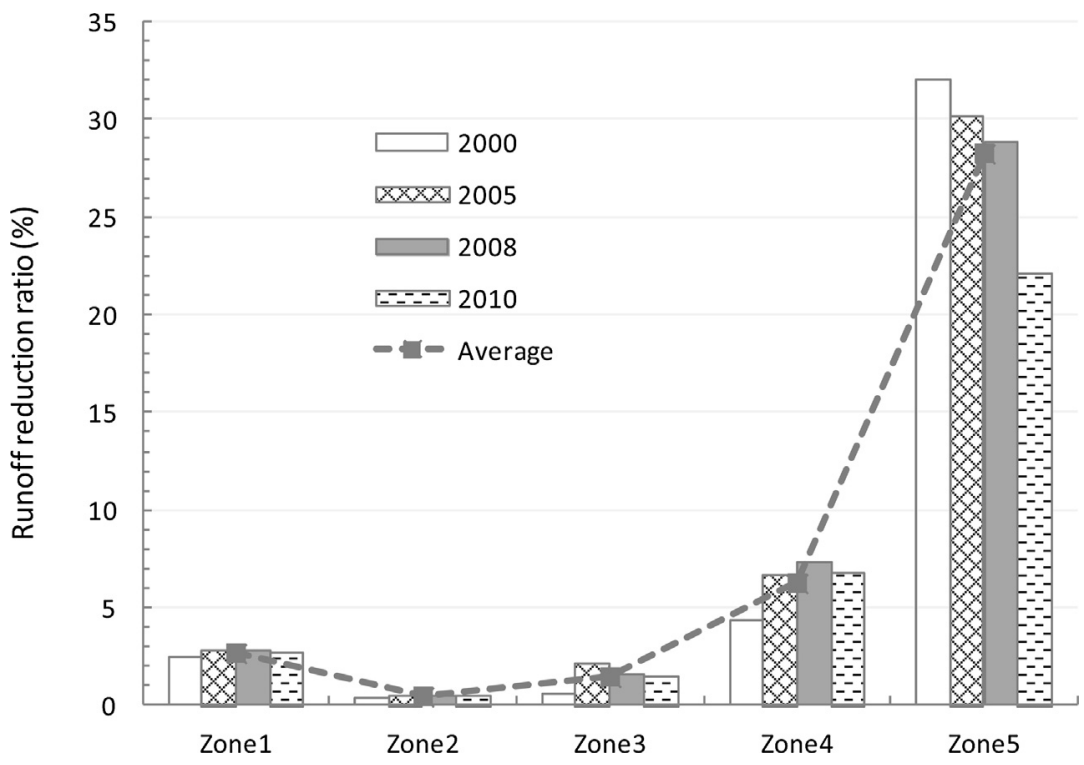

Fig. 5. Ratios of rainwater runoff reduction across different regions. The largest runoff reduction capacity was in Zone 5 , followed by Zones 4 , 1 , 3 , and 2 .

the fourth and fifth ring roads) and Zone 3 (between the third and fourth ring roads), which recorded mean runoff reduction capacities of $6 \%, 3 \%$, and $1.5 \%$, respectively. The minimum stormwater runoff reduction was $0.5 \%$ in Zone 2 (between the second and third ring roads). These differences depended on the green space areas in each zone and landscape patterns of the urban green spaces. From the perspective of dynamic change, the rainwater runoff reduction ratios in Zones 1 and 2 indicated minimal changes from 2000 to 2010 , whereas the runoff reduction capacity in Zone 5 clearly exhibited a decreasing trend in the $2000-2010$ period. By contrast, a large variation in Zones 3 and 4 were observed, with the runoff reduction capacity initially increasing and then decreasing.

The patchiness of the urban green space landscape has important implications for surface runoff generation. Patchiness is largely due to the differences in the landscape patterns of urban green spaces. In this study, a strong positive correlation was noted between runoff reduction capacity, LPI, and AI. Thus, an increase in the LPI or AI expands the role of rainwater runoff reduction facilitated by urban green spaces. The urban green spaces in Zone 5 recorded large LPI and AI values, which led to high connectivity such that the rainwater runoff tended to be minimal. The landscape metrics for all periods significantly decreased. This result can be associated with the diminished magnitude and capacity for runoff reduction in the urbanization of the study area. The comparative analysis of the type, area, and landscape metrics between Zones 1 and 2 is presented in Table 3 . The green space in Zone 1 was composed primarily of grass and forest and had large LPI and $\mathrm{AI}$, thus promoting the role of rainwater runoff reduction. By contrast, the green space in Zone 2 consisted of grass, forest, farmland, and wasteland, thereby accounting for large runoff coefficients. The landscape metrics of the LPI and AI were relatively small, resulting in the poor role of rainwater runoff reduction. Therefore, the landscape patterns of the urban green space in Zone 1 should be recommended for rapidly developing urban areas such as Beijing.

\section{Discussion}

Given the conditions of global climate change and rapid urbanization, clear guidance is necessary for the local authorities and public to formulate the best plan for urban green space management. Beijing was subject to major land cover changes at the beginning of the 21st century. Housing and agricultural activities, as well as forest, river, and other land uses, shifted as a result of urbanization. Land cover underwent significant changes in Beijing in the 2000-2010 period. This observation is consistent with most of the land use changes studied or scenarios that highlighted significant decreases in the areas and landscape metrics of urban green spaces (Fu, 2006; Mao et al., 2012; Wang et al., 2010). Land use changes modify hydrological processes over a range of temporal and spatial scales (Ali, Khan, Aslam, \& Khan, 2011). On July 21, 2012, Beijing suffered the heaviest rain and overall reached the torrential level since 1951 . The disaster affected 1.9 million populations and had aroused wide concerns in China. Several studies have demonstrated that the risk change of storm flooding in an urban center can be partly attributed to the rapid replacement of natural ecosystems by impervious urban surfaces (Hu et al., 2013; Liu, 2009; Shepherd, 2006; Zhong et al., 2013). A combination of a land use scenario and a hydrological model has been considered as an appropriate approach to quantify this effect (Ali et al., 2011). Defining a critical green space threshold for runoff reduction is a complex task because of the effects of land cover changes relative to several factors, such as magnitude, type, spatial location, and climatic effects (Fox et al., 2012). The present study assumed climatic and soil factors as constant and concluded with rainwater runoff reduction rates ranging from $17 \%$ to $23 \%$ across different years. This finding is similar to the results of previous studies. Li et al. (2009) employed the CITY-green model and reported that urban green spaces in Shenzhen, China, reduce annual surface runoff by $30 \%$ and peak flows by over $40 \%$. Given the higher rainfall amount and frequency in the southern region than in the northern region of China, the role of runoff reduction provided by urban green spaces in Shenzhen should be superior to that in Beijing.

However, the present study has several limitations. The spatial variation of storm rainfall in the summer was excluded. In addition to land cover, other factors (i.e., soil properties) can contribute to runoff generation. Although the integrated models such as SWMM and SCS-CN can accurately assess hydrological responses relative to land use change, applications remain difficult because of data scarcity. The runoff parameters from the field observations were averaged and kept constant in all of the processes. However, the runoff coefficients during floods would be very different from the long term averages. The proportion of an extreme rainfall that is 
Table 3

Comparison of type, area, and landscape metrics of urban green spaces between Zones 1 and 2.

\begin{tabular}{|c|c|c|c|c|c|c|c|c|}
\hline \multirow[t]{2}{*}{ Year } & \multicolumn{2}{|c|}{ Type } & \multicolumn{2}{|c|}{ Area } & \multicolumn{2}{|c|}{ LPI } & \multicolumn{2}{|c|}{$\mathrm{AI}$} \\
\hline & Zone 1 & Zone 2 & Zone 1 & Zone 2 & Zone 1 & Zone 2 & Zone 1 & Zone 2 \\
\hline 2000 & Grass and forest & All & 4.35 & 5.39 & 2.59 & 0.77 & 80.36 & 69.35 \\
\hline 2005 & Grass and forest & All & 4.89 & 6.74 & 2.79 & 0.87 & 79.51 & 71.93 \\
\hline 2008 & Grass and forest & All & 4.93 & 6.24 & 2.74 & 0.87 & 78.85 & 70.49 \\
\hline 2010 & Grass and forest & All & 4.86 & 6.14 & 2.74 & 0.87 & 78.80 & 70.27 \\
\hline
\end{tabular}

"All" represents grass, forest, farmland, and wasteland.

reduced by green space is usually much less the average proportion expressed by the average type of coefficients in this study. We must remember that in such extreme events as "7.21 event" in 2012, the surfaces get so wet after a certain amount of rain that every drop more rain immediately runs of concrete, grass and trees at virtually the same rate. Therefore, further research should be conducted to determine the role of runoff reduction within the urban green spaces of urbanized areas.

Despite these limitations, our study provides a reference point for public and government organizations to maximize benefits while controlling costs. Climate change and urban sprawl present threats and opportunities for urban green spaces. This study highlights the significant potential of the use of sustainable urban green spaces to reduce surface runoff particularly at the local level. Excess rainwater can be stored and used to irrigate green spaces in drought periods. The annual economic benefit for rainwater runoff reduction provided by urban green spaces in Beijing was approximately 1.34 billion RMB, which was equivalent to three-quarters of the maintenance cost of Beijing's green spaces (Zhang et al., 2012). In addition, the green spaces in Beijing could absorb $3.33 \times 10^{12} \mathrm{~kJ}$ of heat via evapotranspiration during the entire summer. The cooling effect largely reduced air conditioning demand and $\mathrm{CO}_{2}$ emission (Zhang, Xie, Gao, \& Yang, 2014). However, the functionality of the green spaces depends on their location and structure (Gill et al., 2007). Thus, opportunities to enhance a green cover requires going to where structural changes occur. Green space also assists in reducing runoff through engineered sustainable drainage systems, except such things as grassed waterways and flood detention ponds, as well as keeping flood plains for floods. In addition, specific knowledge on rainwater runoff reduction within urban green spaces across different regions can contribute to the policy design for urban environmental management.

\section{Conclusions}

This study investigated land cover changes in Beijing in the context of rapid urbanization and estimated the role of urban green spaces in reducing stormwater runoff between 2000 and 2010. The green spaces in Beijing were rapidly decreased by $199 \mathrm{~km}^{2}$ from 2000 to 2010 at the expense of agricultural lands. Green landscapes became considerably isolated and fragmented as well. These changes occurred mainly in the areas between the fifth and sixth ring roads. Unlike impervious surfaces, the urban green spaces in Beijing could control $17 \%$ to $23 \%$ of the rainwater runoff annually. Thus, runoff reduction capacity varies with the dominant type and landscape pattern of urban green spaces, under similar rainfall conditions. This variation indicates a potential for water-logging risk reduction through urban green space management in Beijing. The findings of this study provide several references for many highly urbanized areas that suffer from water-logging risk. The optimal landscape patterns should be recommended as urban green space arrangements within the second ring road. In this way, policies can be employed to encourage the optimal structure and composition of urban green spaces through green space strategies. City managers should focus greatly on the role of urban green spaces in rainwater regulation and on the scientific management of urban green spaces.

\section{Acknowledgments}

This study was supported by the National Natural Science Foundation of China (No. 31200531) and the National Science and Technology Support Program (No. 2012BAC01B08). We thank the Beijing Forestry Survey and Design Institute for providing the green space inventory data and RapidEye images used in this study.

\section{References}

Alberti, M. (2009). Advances in urban ecology integrating humans and ecological process in urban ecosystems. New York: Springer Science+Business Media.

Ali, M., Khan, S. J., Aslam, I., \& Khan, Z. (2011). Simulation of the impacts of land-use changes on surface runoff of Lai Nullah Basin in Islamabad, Pakistan. Landscape and Urban Planning, 102, 271-279.

Armson, D., Stringer, P., \& Ennos, A. R. (2013). The effect of street trees and amenity grass on urban surface water runoff in Manchester, UK. Urban Forestry E' Urban Greening, 12, 282-286.

Bartens, J., Day, S. D., Harris, J. R., Dove, J. E., \& Wynn, T. M.(2008). Can urban tree roots improve infiltration through compacted subsoils for stormwater management? Journal of Environmental Quality, 37, 2048-2057.

Battiata, J., Collins, K., Hirschman, D., \& Hoffmann, G. (2010). The runoff reduction method. Journal of Contemporary Water Research \& Education, 146, 11-21.

Bautista, S., Mayor, A. G., Bourakhouadar, J., \& Bellot, J. (2007). Plant spatial pattern predicts hillslope runoff and erosion in a semiarid Mediterranean landscape. Ecosystems, 10,987-998.

Beijing Statistical Bureau. (2010). Beijing statistical yearbook. Beijing: China Statistics Press (in Chinese)

Bolund, P., \& Hunhammar, S. (1999). Ecosystem services in urban areas. Ecological Economics, 29(2), 293-302.

Chen, J. G., Wang, H. C., Zhang, S. H., Su, D. B., Zhao, F., \& Kong, G. (2011). Causal analysis and case study of the road ponding in Beijing city. Water E Wastewater Engineering, 37, 37-40 (in Chinese).

City of Seattle. (2008). The effects of trees on stormwater runoff. Seattle, WA: Herrera Environmental Consultant, Inc.

Dong, X., Du, P. F., Li, Z. Y., Yu, Z. R., Wang, R., \& Huang, J. L. (2008). Hydrology and pollution characteristics of urban runoff: Beijing as a sample. Environmental Science, 29(3), 607-612.

Ellis, T. W., Leguédois, S., Hairsine, P. B., \& Tongway, D. J. (2006). Capture of overland flow by a tree belt on a pastured hillslope in south-eastern Australia. Australian Journal of Soil Research, 44, 117-125.

Fiener, P., Auerswald, K., \& Van Oost, K. (2011). Spatio-temporal patterns in land use and management affecting surface runoff response of agricultural catchments - A review. Earth-Science Reviews, 106, 92-104.

Fohrer, N., Haverkamp, S., \& Frede, H. G. (2005). Assessment of the effects of land use patterns on hydrologic landscape functions: Development of sustainable land use concepts for low mountain range areas. Hydrology Process, 19, 659-672.

Fox, D. M., Witz, E., Balnc, V., Souliéa, C., Navarro, P. M., \& Dervieux, A. (2012). A case study of land cover change (1950-2003) and runoff in a Mediterranean catchment. Applied Geography, 32, 810-821.

$\mathrm{Fu}, \mathrm{X}$. (2006). Analysis of landscape structure of Beijing park system based on GIS. Journal of Beijing Union University (Natural Sciences), 20(2), 80-84.

Fu, X. (2012). Urban green spaces in Beijing: Pattern, process, function and agreeableness. Beijing: Academy Press.

Gao, P., \& Wang, L. X. (1993). Study on the benefits of the water-reserving forest in the upper reaches of Miyun reservoir. Bulletio of Soil and Water Conservation, 13(1), 24-29.

Gill, S. E., Handley, J. F., Ennos, A. R., \& Pauleit, S. (2007). Adapting cities for climate change: The role of the green infrastructure. Built Environment, 33(1), 115-133.

Grimm, N. B., Faeth, S. H., Golubiewski, N. E., Redman, C. L., Wu, J. G., Bai, X. M., et al. (2008). Global change and the ecology of cities. Science, 319, 756-760.

Gu, X. T., Li, N., Zhou, Y., \& Wu, J. D. (2013). Thinking on urban waterlogging disaster defense initiated by $7-21$ extraordinary rainstorm in Beijing. Journal of Natural Disasters, 2, 1-6. 
Guo, C. A., \& Deng, L. M. (2011). Analysis and countermeasure of waterlogging in central urban area of Guangzhou. China Water \& Wastewater, 27(10), 25-28 (in Chinese).

Guo, X. L., Xu, J.W., \& Lv, X. G. (2007). Effect of spatial structure of typical urban underlying surface on rainfall infiltration rate. Journal of Soil and Water Conservation, 21(4), 60-62, 66

He, H. S., DeZonia, B. E., \& Mladenoff, D. J. (2000). An aggregation index (AI) to quantify spatial patterns of landscapes. Landscape Ecology, 15, 591-601.

Hu, H. B., Xuan, C. Y., \& Zhu, L. S. (2013). The pre-event risk assessment of Beijing urban flood. Journal of Applied Meteorological Science, 24(1), 99-108.

Huang, M. X., Zhou, C. H., Zhang, S., \& Zhang, X. M. (2003). Bioavailable phosphorus export by surface runoff from agricultural field plots in Guanting watershed, Beijing. Journal of Lake Sciences, 15(2), 118-124.

Inkiläinen, E. N. M., McHale, M. R., Blank, G. B., James, A. L., \& Nikinmaa, E. (2013). The role of the residential urban forest in regulating throughfall: A case study in Raleigh, North Carolina, USA. Landscape and Urban Planning, 119, 91-103.

Jencso, K. G., McGlynn, B. L., Gooseff, M. N., Wondzell, S. M., Bencala, K. E., \& Marshall, L. A. (2009). Hydrologic connectivity between landscapes and streams: Transferring reach-and plot-scale understanding to the catchment scale. Water Resource Research, 45, W04428. http://dx.doi.org/10.1029/2008WR007225

Kuang, W. H., Liu, J. Y., Zhang, Z. X., Lu, D. S., \& Xiang, B. (2013). Spatiotemporal dynamics of impervious surface areas across China during the early 21 st century. Chinese Science Bulletin, 58(14), 1691-1701.

Lan, M., \& Yang, J. Y. (2009). Causes of waterlogging in the road of Beijing and countermeasures for prevention and control. Water \& Wastewater Engineering, 35, $71-73$ (in Chinese).

Lexartza-Artza, I., \& Wainwright, J. (2009). Hydrological connectivity: Linking concepts with practical implications. Catena, 79, 146-152.

Li, C. Y. (2012). Ecohydrology and good urban design for urban storm water-logging in Beijing, China. Ecohydrology \& Hydrobiology, 12(4), 287-300.

Li, P. W., Li, G. C., Chen, L., Yuan, X. Z., \& Xu, F. (2009). Analysis of Shenzhen's vegetation: Flood control and ecological benefit. Journal of Natural Resources, 24(7), $1223-1233$

Liu, N., Wang, K. L., \& Duan, Y. F. (2011). Analysis on the responses of flood storage capacity of Dongting Lake to the changes of landscape patterns in Dongting Lake area. Acta Ecologica Sinica, 32(15), 4641-4650 (in Chinese).

Liu, Z. Y. (2009). Analysis of characteristics and cause of urban storm runoff change and discussion on some issues. Journal of China Hydrology, 29(3), 55-58 (in Chinese).

Mao, X. G., Song, J. P., Yang, H. Y., \& Zhao, Q. (2012). Changes of the spatial pattern of Beijing city parks from 2000 to 2010. Progress in Geography, 31(10), 1295-1306 (in Chinese).

Mentens, J., Raes, D., \& Hermy, M. (2006). Green roofs as a tool for solving the rainwater runoff problem in the urbanized 21st century? Landscape and Urban Planning, 77, 217-226

Mu, F. Y., Zhang, Z. X., Chi, Y. B., Liu, B., Zhou, O. B., Wang, C. Y., et al. (2007). Dynamic monitoring of built-up area in Beijing during 1973-2005 based on multi-original remote sensed images. Journal of Remote Sensing, 11(2), 257-268 (in Chinese).

National Bureau of Statistics of China, \& Department of Urban \& Social Economic Survey. (2009). China city statistical yearbook. Beijing: China Statistics Press.

Nippgen, F., McGlynn, B. L., Marshall, L. A., \& Emannuel, R. E. (2011). Landscape structure and climate influences on hydrologic response. Water Resource Research, 47 . W12528. http://dx.doi.org/10.1029/2011WR011161

Parrish, D. D., \& Zhu, T. (2009). Clean air for megacities. Science, 326, 674-675.

Pickett, S. T. A., Cadenasso, M. L., Grove, J. M., Boone, C. G., Groffman, P. M., Irwin, E., et al. (2011). Urban ecological systems: Scientific foundations and a decade of progress. Journal of Environment Management, 92, 331-362.

Pitt, M. (2008). The Pitt review. Learning the lessons from the 2007 floods. London: Cabinet Office.

Quan, R. S., Liu, M., Lu, M., Zhang, L. J., Wang, J. J., \& Xu, S. Y. (2010). Waterlogging risk assessment based on land use/cover change: A case study in Pudong New Area, Shanghai. Environmental Earth Sciences, 61(6), 1113.

Schröder, B. (2006). Pattern, process, and function in landscape ecology and catchment hydrology - How can quantitative landscape ecology support predictions in ungauged basins? Hydrology and Earth System Sciences, 10, 967-979.

Shepherd, J. M. (2006). Evidence of urban-induced precipitation variability in arid climate regimes. Journal of Arid Environments, 67(4), 607-628.

Soulis, K. X., Valiantzas, J. D., Dercas, N., \& Londra, P. A. (2009). Analysis of the runoff generation mechanism for the investigation of the SCS-CN method applicability to a partial area experimental watershed. Hydrology and Earth System Sciences Discussions, 6, 373-400.

Sun, T. J., Wu, J. Y., Xiao, C. L., \& Teng, W. J. (2009). Effects of different types of vegetations on soil and water conservation in the Miyun reservoir buffer zone. Journal of Natural Resources, 24(7), 1146-1154.

Sun, Z. H., Feng, S. Y., Yang, Z. S., \& Wu, H. S. (2007). Primary analysis of the precipitation characteristics for Beijing during the period from 1950 to 2005. Journal of Irrigation and Drainage, 26(2), 12-16 (in Chinese).

United Nations, Department of Economic and Social Affairs, Population Division (2010). World population prospects: The 2009 revision, New York.

United Nations, Department of Economic and Social Affairs, Population Division. (2012). World population prospects: The 2011 revision, New York.

Wang, J., Ma, L. Y., Wang, X. J., Liu, J., Zhang, W. J., \& Wan, W.(2010). Landscape pattern of green land in urban parks in the city proper of Beijing. Journal of Northwest Forestry University, 25(4), 195-199.

Wheater, H., \& Evans, E. (2009). Land use, water management and future flood risk. Land Use Policy, 26S, 251-264.

Xiao, R. B., Ouyang, Z. Y., Cai, Y. N., \& Li, W. F. (2007). Urban landscape pattern study based on sub-pixel estimation of impervious surface. Acta Ecologica Sinica, 27(8), 3189-3197 (in Chinese).

Yang, J., \& Myers, M. (2007). Study of stormwater runoff reduction by greening vacant lots in North Philadephia. In Proceeding of 2007 Pennsylvania stormwater management symposium October 17-18, Philadelphia, Pennsylvania.

Yang, L. W., Shi, Q. F., Li, C. Z., \& Zhang, L. H. (1994). Study on storm runoff in small scrub watersheds on Xishan mountain in Beijing. Forest Research, 7(5), 506-511.

Yin, S. F. (2009). Discussions on some questions of rainwater and flood utilization in Beijing city. Beijing Water, S1, 77-79 (in Chinese).

Yin, Z. E., Yin, J., Xu, S. Y., \& Wen, J. H. (2011). Community-based scenario modeling and disaster risk assessment of urban rainstorm waterlogging. Journal of Geographical Sciences, 21(2), 274-284.

You, F. C., Shi, Z. Y., \& Wu, H. Y. (2011). Correlation analysis between water-logging events and rainfall intensity in the same period in Beijing urban area. In The 28th Chinese Meteorological Society Annual Conference-S10 public meteorological service policy system mechanism and discipline construction Xiamen city, Fujian province, China, (in Chinese).

Yu, Z. M., \& Wang, L. X. (1999). Benefits of water conservation forest. Beijing: China Forestry Press.

Yue, N. (2007). The characteristics of water resource and sustainable utilization in Beijing.Journal of Capital Normal University (Nat Sci), 28(3), 107-113 (in Chinese).

Zhang, B., Xie, G. D., Zhang, C. Q., \& Zhang, J. (2012). The economic benefits of rainwater-runoff reduction by urban green spaces: A case study in Beijing, China. Journal of Environmental Management, 100, 65-71.

Zhang, B., Xie, G. D., Gao, J. X., \& Yang, Y. (2014). The cooling effect of urban green spaces as a contribution to energy-saving and emission-reduction: A case study in Beijing, China. Building and Environment, 76, 37-43.

Zhang, S. C., Li, J. B., Tang, L. H., \& Xie, S. H. (2002). Analysis of the precipitationrunoff for rainwater utilization in residential quarter in Beijing. In 2002 Beijing international symposium on rainwater utilization and treated water reuse Beijing.

Zhang, W., \& Ouyang, L. C. (2011). Reasons and count measures of urban waterlogging in Guangzhou. Guangdong Meteorology, 33(3), 49-53.

Zhong, Y. D., Jia, Y. W., \& Li, Z. W. (2013). Spatial and temporal changes of maximum $1 \mathrm{~h}$ precipitation intensity in Beijing region in last 53 years. Journal of China Hydrology, 33(1), 32-37.

Ziegler, A. D., Giambelluca, T. W., Plondke, D., Leisz, S., Tran, L. T., Fox, J., et al. (2007) Hydrological consequences of landscape fragmentation in mountainous northern Vietnam: Buffering of Hortoniam overland flow. Journal of Hydrology, 337, 52-67. 